\title{
A Case Study on the Impacts of Connected Vehicle Technology on No-Notice Evacuation Clearance Time
}

\author{
Karzan Bahaaldin, ${ }^{1}$ Ryan Fries, ${ }^{2}$ Parth Bhavsar, ${ }^{3}$ and Plaban Das ${ }^{3}$ \\ ${ }^{1}$ Johnson, Mirmiran, \& Thompson, 9201 Arboretum Parkway, Suite 310, Richmond, VA 23236, USA \\ ${ }^{2}$ Department of Civil Engineering, Southern Illinois University Edwardsville, Box 1800, Edwardsville, IL, USA \\ ${ }^{3}$ Department of Civil and Environmental Engineering, Rowan University, 201 Mullica Hill Road, Glassboro, NJ 08028, USA \\ Correspondence should be addressed to Karzan Bahaaldin; kbahaaldin@jmt.com
}

Received 28 December 2016; Revised 22 July 2017; Accepted 10 September 2017; Published 11 October 2017

Academic Editor: Dongjoo Park

Copyright (c) 2017 Karzan Bahaaldin et al. This is an open access article distributed under the Creative Commons Attribution License, which permits unrestricted use, distribution, and reproduction in any medium, provided the original work is properly cited.

\begin{abstract}
No-notice evacuations of metropolitan areas can place significant demands on transportation infrastructure. Connected vehicle (CV) technology, with real-time vehicle to vehicle and vehicle to infrastructure communications, can help emergency managers to develop efficient and cost-effective traffic management plans for such events. The objectives of this research were to evaluate the impacts of CVs on no-notice evacuations using a case study of a downtown metropolitan area. The microsimulation software VISSIM was used to model the roadway network and the evacuation traffic. The model was built, calibrated, and validated for studying the performance of traffic during the evacuation. The researchers evaluated system performance with different $\mathrm{CV}$ penetration rates (from 0 to 30 percent CVs) and measured average speed, average delays, and total delays. The findings suggest significant reductions in total delays when CVs reached a penetration rate of 30 percent, albeit increases in delays during the beginning of the evacuation. Additionally, the benefits could be greater for evacuations that last longer and with higher proportions of $\mathrm{CV}$ s in the vehicle stream.
\end{abstract}

\section{Introduction}

Evacuating people to safe places during natural and manmade disasters has been required throughout history. While many factors affect the evacuation process, the performance of the transportation system is an important factor that cannot be neglected. Transportation operation engineers have a responsibility to ensure that the roadways function at their optimum capacities, in order to evacuate people from disaster areas in the shortest possible time. Reducing evacuation time can prevent loss of life; property damage; and decrease motorist delay, fuel use, and emissions.

Evacuations can be categorized into two main types, based on the available time to respond: no-notice and short notice. The first type is considered when a disaster occurs without prior notice such as terrorist attacks, nuclear disasters, and earthquakes. The second type is when responders have some short notice such as wildfires, hurricanes, and flooding. It is preferred to have evacuation plans for both short-notice and no-notice cases prior to the disaster, but it is more necessary for no-notice evacuations [1].

The Illinois Department of Transportation (IDOT) developed an evacuation traffic management plan for the East St. Louis Metropolitan area in 2013. When developing these plans, authors found that there were some parts of the transportation system that performed poorly. The issue occurred because vehicle conflicts at merge areas, diverge areas, and weaving segments on the roadways. This study focused towards evaluating the impact of connected vehicles (CVs) on the traffic performance at these problematic areas and the overall network.

The primary way the CVs could influence the performance of an evacuation is by exchanging real-time information about the traffic conditions downstream. The CVs could use this knowledge to take actions accordingly. These actions could include adjusting speed, changing lanes, or rerouting if possible. The selection of these actions will be based on the information type and time and the network characteristics. 
TABLE 1: Review of previous strategies to reduce evacuation time.

\begin{tabular}{|c|c|c|}
\hline Strategies & Challenges & Authors \\
\hline Contraflow or lane reversal & $\begin{array}{l}\text { Unplanned contraflow orders, estimation } \\
\text { of the number of vehicles, and how } \\
\text { vehicles would enter contraflow lanes }\end{array}$ & $\begin{array}{l}\text { Pel et al., } 2008 \text { [5], Final Report-NJIT, } 2007 \text { [6], } \\
\text { Hamza-Lup et al., } 2004 \text { [7], Tuydes and } \\
\text { Zilliaskopoulos, } 2004 \text { [8], Litman, } 2006 \text { [9], } \\
\text { Buckley and Jernigan, } 2001 \text { [10], Kim et al., } \\
2008 \text { [11], Wolshon and Lambert, } 2004 \text { [12] }\end{array}$ \\
\hline Dynamic routing & $\begin{array}{l}\text { Level of instructions, roadway network } \\
\text { structure, available traffic information, } \\
\text { and traveler compliance }\end{array}$ & $\begin{array}{l}\text { Pel et al. } 2010 \text { [13], Urbanik II } 2000 \text { [14], } \\
\text { Stepanov and Smith, } 2009 \text { [15], Chen and } \\
\text { Zhan, } 2008 \text { [16], Liu et al., 2008 [17] }\end{array}$ \\
\hline Priority signal control & $\begin{array}{l}\text { Priority category and number of } \\
\text { destinations }\end{array}$ & $\begin{array}{l}\text { Chiu and Zheng, } 2007 \text { [18], Kimms and } \\
\text { Maassen, } 2012 \text { [19], Yi et al., } 2012 \text { [20] }\end{array}$ \\
\hline Intersection crossing elimination & Merging and postdisaster evacuation & $\begin{array}{l}\text { Ardekani and Hobeika, } 1988 \text { [21], Cova and } \\
\text { Johnson, } 2003 \text { [22], Kalafats and Peeta, 2009 } \\
\text { [23], Chang and Edara [4], Jahangiri et al., } 2014 \\
\text { [24] }\end{array}$ \\
\hline Network/route optimization & $\begin{array}{l}\text { Driver behavior during evacuation and } \\
\text { calibration }\end{array}$ & $\begin{array}{l}\text { Liu et al., } 2006 \text { [25], Sbayti and Mahmassani, } \\
2006 \text { [26], Chiu et al., } 2007 \text { [27], Hamza-Lup et } \\
\text { al., } 2007 \text { [28], Xie and Turnquist, } 2009 \text { [29], Xie } \\
\text { et al., } 2010 \text { [30], Liu et al. [31], Murray-Tuite } \\
\text { and Wolshon [32], Handford and Rogers [33], } \\
\text { Ni [34] }\end{array}$ \\
\hline Car following techniques & $\begin{array}{l}\text { Unrealistic driver behavior/crash } \\
\text { avoidance }\end{array}$ & Hamdar and Mahmassani [35] \\
\hline
\end{tabular}

The next section includes a summary of reviewed literature on evacuations and CVs. The methods, analysis, and conclusions follow, each in separate sections.

\section{Review of Previous Literature}

The reviewed studies and research in this section include the literature on evacuations including traffic simulations and evaluating connected vehicles during evacuations. Previous researchers have considered various strategies to improve the overall evacuation process, reduce the congestion on the evacuation routes, and optimize the use of resources and infrastructure. Communication at various levels and stages is incorporated in these strategies. There is a consensus that, without effective communication, advanced systems such as ITS will be less useful [2].

The authors have performed extensive review of the existing literature which is summarized in Tables 1-3. Table 1 summarizes previous work evaluating strategies to improve evacuation traffic flow; Table 2 lists studies of CVs that relate to evacuation; and Table 3 includes a review of research on the issues and solutions related to CVs. The research most-closely related to that described herein developed the Response, Emergency Staging and Communications, Uniform Management, and Evacuation (RESCUME) application bundle, specifically, the Emergency Communications for Evacuation (EVAC). This system was evaluated for a shortnotice evacuation scenario for New Orleans, LA, finding a congestion reduction of approximately 20 percent [3]. The study herein differs because it focuses on a no-notice evacuation scenario at a network where route choices are limited due to a major river crossing. Another related recent study by Chang and Edara proposed an autonomous reservation-based intersection control for emergency evacuations [4]. Their proposed algorithm was evaluated using traffic-microsimulation model. The study resulted in a $29 \%$ increase in average speed and $88 \%$ reduction in delay [4].

As shown in Table 1, many studies tested the impact of various elements on the efficiency of an evacuation. In addition, the selection of proper Measures of Effectiveness (MoEs) to include during evacuation simulations is important to improve modeling practices. The most commonly used MoEs are network clearance time, total delay, evacuation exposure, average speed, and travel times. Total evacuation time (i.e., network clearance time) is considered the most straightforward indicator that shows the time when all the evacuees left the at-risk area [36].

Regarding connected vehicle literature, the most-related studies reviewed were on the topic of CV related to incidents and/or evacuations. Table 2 lists the most relevant studies and demonstrates that limited research has been conducted on no-notice evacuation. These studies include a variety of vehicle communication technologies used to identify and overcome CV challenges and limitations. Although these studies focus on how CV capabilities can be utilized in traffic on a daily basis during normal and sometimes emergency conditions, these capabilities have the potential of improving traffic flow during evacuations.

Similar to any new technology, the use of CVs is expected to face some limitations and issues that need to be addressed before wider implementation. To overcome these issues and others, researchers investigated solutions to the issues they considered critical as shown in Table 3. 
TABLE 2: Review of existing connected vehicles technology with possible applications during evacuations.

\begin{tabular}{|c|c|c|}
\hline Modeling approach & Development & Proposed by \\
\hline $\begin{array}{l}\text { Identifying and managing the state of the evacuation } \\
\text { routes and directing the responders and evacuees to the } \\
\text { desired routes }\end{array}$ & $\begin{array}{l}\text { Technology assessment with gap } \\
\text { analysis }\end{array}$ & Kantowitz and LeBlanc, 2006 [37] \\
\hline Directing emergency vehicles to less congested routes & Algorithm development & Rizvi et al., 2007 [38], Mohandas et al. [39] \\
\hline $\begin{array}{l}\text { Using data fusion to dispatch and direct emergency } \\
\text { vehicles during postdisaster environment }\end{array}$ & $\begin{array}{l}\text { Mathematical model development } \\
\text { and a case study }\end{array}$ & Jotshi et al., 2009 [40] \\
\hline $\begin{array}{l}\text { Unmanned aerial vehicles with wireless communication } \\
\text { system in disaster management }\end{array}$ & Architecture development & Maza et al., $2011[41]$ \\
\hline $\begin{array}{l}\text { Using cloud-based data system to manage and distribute } \\
\text { evacuees to optimize the network capacity }\end{array}$ & $\begin{array}{l}\text { Algorithm development and } \\
\text { simulation to validate }\end{array}$ & Alazawi et al., 2012 [42] \\
\hline $\begin{array}{l}\text { Disseminating information about an approaching } \\
\text { emergency vehicle through the roadside units }\end{array}$ & $\begin{array}{l}\text { Architecture development and } \\
\text { simulation }\end{array}$ & Bermejo et al., 2013 [43] \\
\hline
\end{tabular}

TABLE 3: Identified issues and proposed solutions for CVs.

\begin{tabular}{lll}
\hline Issue & Solution & Proposed by \\
\hline $\begin{array}{l}\text { CV communication discontinuity in low } \\
\text { traffic }\end{array}$ & $\begin{array}{l}\text { Hybrid use of ad hoc and roadside units } \\
\text { Connectivity in CVs }\end{array}$ & Qin et al. [44], McCall \& Trivedi [45] \\
& $\begin{array}{l}\text { Using smart phone capabilities/current \& } \\
\text { future trends }\end{array}$ & $\begin{array}{l}\text { mAutomotive [46], Andersen [47], Munarriz } \\
\text { [48], Telematics [49] }\end{array}$ \\
Privacy concerns & $\begin{array}{l}\text { Providing information excluding vehicle } \\
\text { ID }\end{array}$ & Fries et al. [50], Abuelela et al. [51] \\
$\begin{array}{l}\text { Driver disruption with information } \\
\text { from/to CV(s) }\end{array}$ & $\begin{array}{l}\text { Auto process of communication data } \\
\text { Higher CV costs relative to traditional }\end{array}$ & Abuelela et al. [51], Adams and Heile [52] \\
vehicles & $\begin{array}{l}\text { Educating people about safety and } \\
\text { long-term economic benefits of CVs }\end{array}$ & Daziano et al. [53], Bansal and Kockelman [54] \\
\hline
\end{tabular}

Emergency evacuations have been widely studied and the plans developed as a result have become an important element for many agencies. Using computer simulation for evaluating evacuation plans is a common practice. Different considerations have been taken when simulating evacuations, such as varying driver behaviors, including the presence of incidents, and varying the levels of information provided/exchanged. Although some studies have focused on information dissemination during evacuations, no previous studies have evaluated the impact of connected vehicles during an evacuation.

\section{Methods}

The area considered in the evacuation process was bounded by the Mississippi River on the west, IL-143 from the north, IL-4 from east, and both I-255 and I-64 from the south. The roadway network within the specified area includes Interstates 55, 70, 64, 255, and 270; IL routes $3,4,15,111,203$, 143,157 , and 159; and US routes 40 and 50. In addition, all interchanges that connect the interstates with the local roads were included. A map showing the routes within the studied area is in Figure 1.

The study year's (2014) traffic volumes on the included roadways were obtained from IDOT [55]. This traffic volume was used as the background traffic in the model before

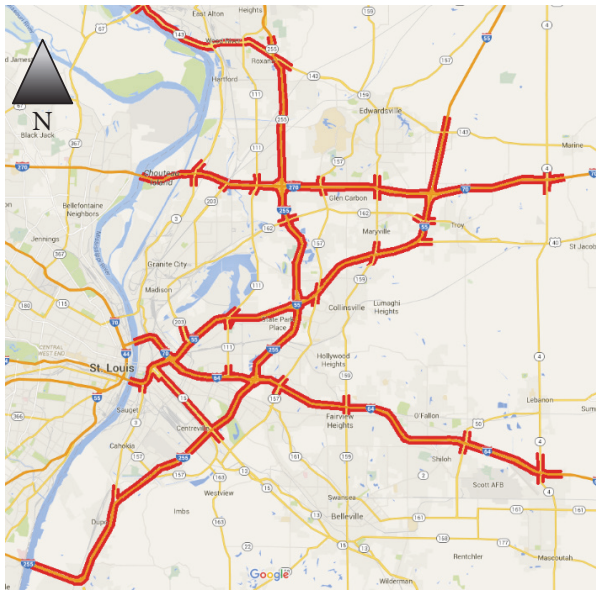

FIGURE 1: Simulated road network (source: Google Maps). Not to scale.

loading the evacuation traffic. The same background traffic is used for all runs which represented the nonpeak weekday traffic for a period of 30 minutes before evacuation traffic enters the network. Heavy vehicle proportion was taken from a $24 \mathrm{~km}$ segment of I-55/70. Traffic signal timing data was collected from the local District of IDOT and site visits. The 
TABLE 4: Data collection and sources [56].

\begin{tabular}{|c|c|c|c|}
\hline Data & Purpose & Sources & Remarks \\
\hline Aerial images & Creating network & $\begin{array}{l}\text { Geographic Department (SIUE) } \\
\text { and Google Website }\end{array}$ & Used as a base for the model \\
\hline Chain of rocks canal bridge & $\begin{array}{l}\text { Ensuring the network reflects } \\
\text { post } 2014\end{array}$ & $\begin{array}{l}\text { IDOT and MODOT approved } \\
\text { design plans }\end{array}$ & $\begin{array}{l}\text { Completed but not updated in } \\
\text { aerial images }\end{array}$ \\
\hline Current traffic volumes & Model calibration & IDOT website & For $24 \mathrm{~km}$ segment of $\mathrm{I}-55,70$ \\
\hline Traffic signal timing & Network modeling & IDOT-District 8 and site visits & Traffic Control \\
\hline Trip O/D matrices & $\begin{array}{c}\text { Loading the network with traffic } \\
\text { volumes }\end{array}$ & $\begin{array}{l}\text { Regional Planning Agency } \\
\text { (EWGCOG) }\end{array}$ & $\begin{array}{l}\text { Reflecting the evacuation } \\
\text { volumes for base year }\end{array}$ \\
\hline Travel times & Model calibration & Site visits & For $24 \mathrm{~km}$ segment of I-55/ I-70 \\
\hline Queue lengths & Model validation & Site visits & Routes $157 \& 159$ \\
\hline Truck percentage & Traffic distribution & Site visits & Segments of I-55, 70, and I-64 \\
\hline Stop signs & Network modeling & Site visits & Traffic control \\
\hline
\end{tabular}

processes of data collection, purpose, and sources are listed in Table 4.

3.1. Software Selection. With the advancement in technology and computing power, the use of computer simulations in traffic analysis has become more common [57, 58]. Some studies on evaluating the traffic simulation software considered both Paramics and VISSIM as appropriate for modeling evacuations compared to other types of modeling $[57,59]$. Studies compared the traffic simulation results with actual traffic data collected, showing that the outputs from traffic simulations were a satisfactory representation of the real world $[60,61]$. VISSIM was selected for the evacuation traffic management study because of its ability to simulate detailed vehicle interactions at specific locations in the transportation network and its ability to produce videos of expected traffic conditions for IDOT training purposes. This software was subsequently chosen for evaluating connected vehicles because a calibrated model was already built and VISSIM supported modeling the connected vehicle communications using its Component Object Model (COM) interface.

3.2. Model Creation. The VISSIM model included 485 links and 910 connectors, totaling 800 centerline kilometers of roadway with various numbers of lanes, equivalent to approximately 1,610 lane-kilometers of roadway. Nodes were created at each junction, totaling 300 .

The 38 traffic signals were recreated in the Synchro 8 [62] and imported into VISSIM. In addition, 2,577 conflict areas were used to represent the various intersections, merges, diverges, and weaving areas in the network.

3.3. Model Calibration and Validation. A $24 \mathrm{~km}$ freeway segment within I-55/70 was selected for calibration. This segment only represented 5 percent of the freeway lanekilometers within the total model area, but it is located in the geographic center of the other modeled roadways (see Figure 2) and assumed to capture the driver behavior of those traveling in the region's road network because it is on the path of most other roadways within the study area.

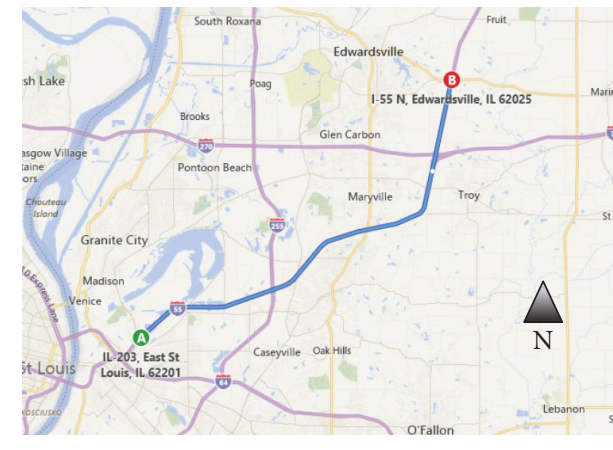

FIgURE 2: Calibration Segment. Not to scale.

Travel times and speed distribution were collected along this segment for both directions of travel. Five travel times for each direction were collected in the field to reach $\geq 99$ percent level of confidence.

The driving behavior was modeled by using the parameters set by Wiedemann 99 in VISSIM, which was more suitable for modeling freeways [63]. It was found from previous literature that some of these parameters such as CC0 (standstill distance), CC1 (headway time), and CC2 ("following" variation) had higher impacts on the results while other parameters such as CC3 (threshold for entering "following") had less influence $[64,65]$. Further information about the calibration of this model can be found in Bahaaldin et al. [56].

A total of 40 iterations were conducted modifying the speed distributions and the driver behavior parameters mentioned earlier during this calibration process until average travel times were within one percent of the actual collected travel times. The model was considered to accurately represent the real-world scenario because it was within one percent of the observed values [66]. To overcome the issue of drivers failing to merge at heavily congested intersections, driver behavior parameters were adjusted to act more aggressively for these specific problematic merging areas as recommended by the software's developers [67]. 
Queue lengths were used to validate the simulation model after calibration because it was a common performance measure used in traffic studies. The queue counts were collected from site visits at the intersections of I-55 and Illinois routes 157 and 159 and then compared to queues that occurred during simulation iterations at the same locations during the same time of day. The results were satisfactory and queue lengths visually matched in all locations without the need for further calibration. Details can be found in the author's previous work [56]. These results showed that the process of calibration and validation was satisfactory as described in previously established methods $[66,68]$.

3.4. Evacuation Traffic Volumes. The East-West Gateway Council of Government (EWGCOG) is the Metropolitan Planning Organization for the St. Louis metropolitan area. This agency worked with the research team to forecast the traffic volumes representing the study target year of 2014. The projected evacuation traffic was provided in O-D matrices that represented three types of vehicles: single occupant vehicles, high occupant vehicles, and trucks. Dynamic assignment was selected for this research because it was more representative of the choices drivers might make during an evacuation. In particular, the study network included alternative routes in several places of the network.

The evacuation traffic was loaded after 30 minutes of background traffic which was allowed to completely distribute to every part of the road network. The evacuation traffic was then mixed with the background traffic that remained on the roadways during the assumed start of the evacuation. Researchers assumed that traffic headings towards the evacuation zones would be diverted by traffic managers and that external-external trips would start choosing alternative routes 10 minutes after an evacuation began, based on real-time traveler information requirements mandated by the Federal Highway Administration [69].

3.5. Model Convergence. The dynamic assignment method used in this study required the convergence of the model. Previous studies found the convergence threshold to range from 10-15 percent due to the fluctuating nature of route selection and traffic distribution [70]. Researchers generally agree that this threshold represents observed traffic patterns and a value of 12 percent was chosen. The convergence was obtained by running the simulation more than 20 iterations.

3.6. Connected Vehicle Modeling. The vehicle communication capabilities were modeled using the Component Object Model (COM) interface provided for VISSIM. The process started with writing a code in Visual Studio 2015 [71] to simulate the communication of travel speeds, delays, and location between CVs.

To model a CV, the research team created a vehicle type "CV" in VISSIM with the characteristics the same as the default "car" vehicle type. To model a mixed traffic stream in which only CVs can communicate with each other, the COM interface was utilized to exchange required data between "CV" types at every simulation time step. Changing the percentage of these vehicles provides various $\mathrm{CV}$ penetration rates in the evacuation traffic stream accordingly.
The required data from the CVs was then collected and evaluated based on the user's need and the appropriate action was applied to the CVs. Based on the observed congested operating speed at a key bottleneck, the code directed all CVs to move to the left lane when the downstream travel speeds were below $32 \mathrm{~km} / \mathrm{h}$ ( 20 miles per hour) at any point with the modeled network; see [72].

The speed of $32 \mathrm{~km} / \mathrm{h}$ was set as the threshold based on the examination of the average speeds of the converged model with no-CVs. The speeds fell below $32 \mathrm{~km} / \mathrm{h}$ on road segments within identified problematic areas. In this study, the researchers tested the assumption that if CVs approach this congestion and maintain the speed of $32 \mathrm{~km} / \mathrm{h}$ or higher, the traffic flow will be more stable with less delays and reduce the overall evacuation time. CVs approaching congested road segments were also guided to select the left lane. The problematic areas were similar to those congested segments during the PM weekday peak hour and included merges, diverges, and weaves on the right side of I-55. It was assumed that guiding the CVs to change to the left lanes in advance would assist in improving the traffic operation at these locations by reducing the right lane utilization.

The researchers varied the penetration rate of CVs from zero (base scenario) to 30 percent, based on a predicted implementation of CVs by the year 2018 [46]. As of 2015, some vehicles are already equipped with communication devices and in the near future, vehicle manufacturers are planning to add more CV features based on the demand [73].

3.7. Model Runs. Processing the data starts from test runs of the VISSIM model, determining the required number of iterations, verifying the calculated number of iterations, extracting the data from the model, and analyzing and comparing different scenarios. From the equation recommended by the VISSIM user manual, the number of iterations $(n)$ was found to be 2.71 . This finding means that three simulation iterations are required to consider that, with a probability of 95 percent, the real mean value of travel times lies within the interval measured value \pm 10 percent. Based on this calculation, all the scenarios were run for at least three iterations.

\section{Findings}

The data from the no-CV and the 30 percent CV scenarios were compared to identify the difference in the performance measures such as average delay and speeds. The findings showed that the two scenarios were identical during the warm-up period when normal background traffic was populating the simulated road network, as expected. The speeds drop rapidly after the start of the evacuation (time interval 1 in Figure 3) due to the addition of the evacuation traffic flows. Both scenarios show the same trends except that the no-CV scenario recorded higher speeds until time interval four. At that time interval, CVs became aware of upcoming congestion and changed their speeds and lane choices accordingly. The findings suggest that the CVs slowed the entire traffic stream during time intervals one to four, likely due to their speed reduction and lane choice in response to downstream 


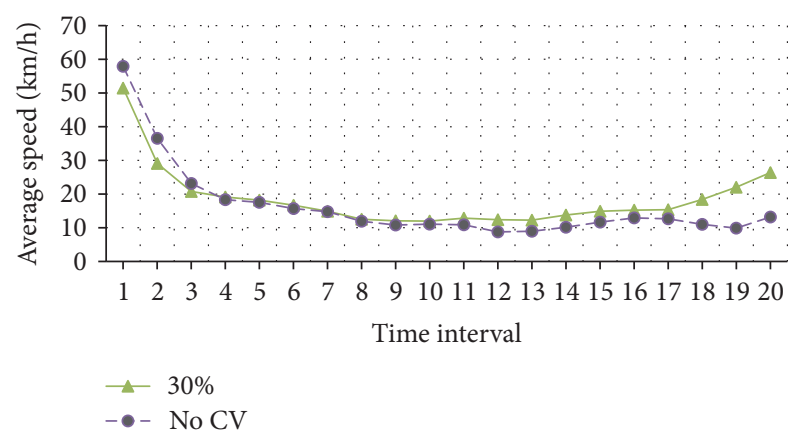

FIgURE 3: Speed comparison, 30 percent CV and no-CV.

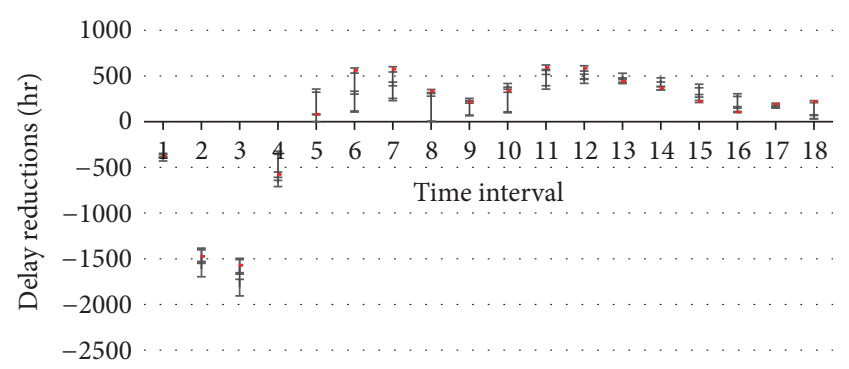

FIGURE 4: Total delay reductions between no-CVs and 30 percent CVs.

congestion. Although the duration in minutes cannot be disclosed, the overall simulated evacuation required several hours to complete in real-time.

The CV's lane changing caused some levels of slowdown within the network. This slowdown likely affected other vehicles, causing slower albeit steadier traffic operation compared to the no-CV scenario. This action likely prevented traffic flow density at key road segments from exceeding the optimum during some time intervals, avoiding the occurrence of unstable traffic flow.

After time interval four, the 30 percent CV scenario demonstrated higher average travel speeds compared to the no-CV scenario. To find if this change was statistically significant a $t$-test was conducted with the assumption that the means were equal. The results from the analysis indicated that there was strong evidence $(p=0.04)$ that the speeds were higher during the 30 percent scenario.

The comparison of total delay displayed in Figure 4 demonstrates the same trend as average speed but shows the level of confidence in the relative difference (delays of no$\mathrm{CV}, 30$ percent $\mathrm{CV}$ ). Each vertical bar displays the extents of 95-percent confidence interval and the bold horizontal dash represents the average vehicle delay in that time interval. The no-CV scenario had significantly less delay during the first four time intervals after the evacuation event began. The 30 percent CV scenario recorded significantly less total delays after time interval four, for the remainder of the evacuation event. A similar pattern was found in the average delay as well.

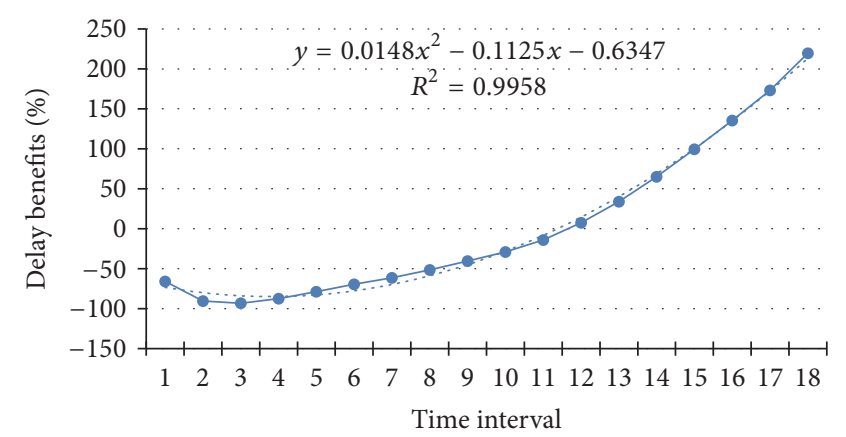

FIGURE 5: Cumulative percent benefits of 30 percent CV scenario.

The benefits from the implementation of the 30 percent $\mathrm{CV}$ scenario varied for each performance measure and some fluctuations were observed at certain time intervals. To gain deeper meaning from the benefits of CVs during an evacuation, a generic relationship of the improvement in total delay was developed. The cumulative percentage of changes from no-CV to 30 percent CV was calculated, for every time interval and a trend line was determined, as shown in Figure 5. The trend line is a representation of the expected benefits of utilizing the communication capabilities of CVs.

The trend line indicates that the benefits from the implementation of CVs had a negative impact during the beginning of an evacuation. All the examined performance measures showed this pattern. The benefits of CVs start to show positive impact after the third interval and continue to increase with time. Cumulative improvements of 60 percent were shown for the network delay during the entire study period. Recall that others predicted a 20 percent improvement because of $\mathrm{CV}$ deployment during a short-notice evacuation [3]. In comparison, the findings imply that CV deployment might benefit no-notice evacuations more than short-notice evacuations. Previous research also suggested an 88 percent reduction in delay for intersections [4]. Thus, CV deployments might see additional benefits when evaluating arterial routes.

This improvement was achieved for the CV scenario because these vehicles were instructed to reduce congestion by optimizing the lane choice whenever the average speed fell below $32 \mathrm{~km} / \mathrm{h}$. The instructions for CVs to change lanes to the left may require slowdowns or stops in the traffic stream, as CVs wait for a proper gap to change lanes. These interactions could have caused more delays during the first few time intervals compared to the no-CV scenarios. CVs will be aware of upcoming congestion and gravitate towards the left lane well-in-advance of a diverging, converging, or weave segments. Non-CVs freely selecting their lane will prefer to stay in the faster lane until either congestion or their route towards their destination requires otherwise.

The results suggest that the traffic stream starts to become more stable after the CVs have completed their lane changes. In addition, CVs will work cooperatively due to less aggressive behavior and prior knowledge about roadway condition, allowing gaps for other vehicles to merge. This lane changing procedure continues when the roadway geometry and speeds are changed. 


\section{Conclusions}

The analyzed data showed that using communication capabilities of CVs can improve the overall traffic performance during a no-notice evacuation in the East St. Louis Metropolitan area. The study compared the average speed, average delays, and total delays. The evaluation of these performance measures suggests that the presence of 30 percent CVs could significantly reduce evacuation traffic delays, compared to a scenario with no-CVs. Specifically, the data analysis considered the impact on the total delay of the network. The results showed that the delay was approximately 60 percent lower for the total study period. It is important to note that the authors assumed that all drivers of CVs in the network will follow directions provided by in-vehicle units. In comparison to other CV evacuation research, these findings indicate that CV deployment might benefit no-notice evacuations more than short-notice evacuations.

Closer analysis of the time intervals throughout the evacuation suggested that the presence of CVs could increase the delay at the start of an evacuation. This increase, approximately 30 percent, was likely due to CV lane changes and speed reduction when informed of upcoming traffic congestion.

The trend line developed from the total delay performance measures indicated that the benefits of the 30 percent CV scenario began after approximately $1 / 3$ of the overall evacuation and increased approximately three percent per time interval.

Overall, the combined findings from this study indicate that the utilization of CV technology can improve the traffic operations during a no-notice evacuation. Increasing the $\mathrm{CV}$ penetration rate can contribute to better traffic performance. The benefits of such implementation are correlated proportionally with the factor of time, where evacuations taking longer could benefit more. Although the specific level of benefits is related to the roadway network and traffic characteristics modeled in this study, the trends are likely transferable.

Future work could evaluate different performance measures, time intervals, roadway networks, and/or traffic distribution to identify if the results are similar. The finding that CVs could improve traffic operations during emergency evacuations is likely transferable.

\section{Conflicts of Interest}

The authors declare that they have no conflicts of interest.

\section{References}

[1] Department of Homeland Security, Mass Evacuation Planning Guide for Major Events, Nascar Pilot, 2008.

[2] U.S.DOT, Intelligent Transportation Systems for Planned Special Events, Federal Highway Administration, Washington, D.C., WA, USA, 2008.

[3] G. Cordahi, D. Roden, B. Wolshon, and W. Yin, Emergency Communications for Evacuation (EVAC) in New Orleans Impact Assessment Report, FHWA, Washington, D.C., WA, USA, 2015.
[4] Y. Chang and P. Edara, "AReBIC: Autonomous reservationbased intersection control for emergency evacuation," in Proceedings of the 2017 IEEE Intelligent Vehicles Symposium (IV), pp. 1887-1892, Los Angeles, CA, USA, June 2017.

[5] A. J. Pel, M. C. J. Bliemer, and S. P. Hoogendoorn, "EVAQ: a new analytical model for voluntary and mandatory evacuation strategies on time-varying networks," in Proceedings of the 11th International IEEE Conference on Intelligent Transportation Systems (ITSC '08), pp. 528-533, Beijing, China, December 2008.

[6] NJIT, Cape May County Hurricane Evacuation and Elevation Study Extension, South Jersey Transportation Planning Organization, New Jersey, NJ, USA, 2007.

[7] G. L. Hamza-Lup, K. A. Hua, and P. Rui, "Enhancing intelligent transportation systems to improve and support homeland security," in Proceedings of the The 7th International IEEE Conference on Intelligent Transportation Systems, pp. 250-255, Washington, WA, USA, 2004.

[8] H. Tuydes and A. Zilliaskopoulos, Network Re-Design to Optimize Evacuation Contraflow, in 83rd Annual Meeting of the Transportation Research Board, 2004.

[9] T. Litman, "Lessons from Katrina and Rita: what major disasters can teach transportation planners," Journal of Transportation Engineering, vol. 132, no. 1, pp. 11-18, 2006.

[10] P. Buckley and I. Jernigan, Southeast Louisiana Hurricane Evacuation Study: Abbreviated Transportation Model Developement and Format, Tallahassee, FL, USA, 2001.

[11] S. Kim, S. Shekhar, and M. Min, "Contraflow transportation network reconfiguration for evacuation route planning," IEEE Transactions on Knowledge and Data Engineering, vol. 20, no. 8, pp. 1115-1129, 2008.

[12] B. Wolshon and L. Lambert, Convertible Roadways and Lanes: a Synthesis of Highway Practice, National Cooperative Highway Research Program, Washington, D.C., WA, USA, 2004.

[13] A. J. Pel, S. P. Hoogendoorn, and M. C. J. Bliemer, "Evacuation modeling including traveler information and compliance behavior," in Proceedings of the 1st International Conference on Evacuation Modeling and Management (ICEM '09), pp. 101-111, September 2010.

[14] T. Urbanik II, "Evacuation time estimates for nuclear power plants," Journal of Hazardous Materials, vol. 75, no. 2-3, pp. 165$180,2000$.

[15] A. Stepanov and J. M. Smith, "Multi-objective evacuation routing in transportation networks," European Journal of Operational Research, vol. 198, no. 2, pp. 435-446, 2009.

[16] X. Chen and F. B. Zhan, "Agent-based modelling and simulation of urban evacuation: relative effectiveness of simultaneous and staged evacuation strategies," Journal of the Operational Research Society, vol. 59, no. 1, pp. 25-33, 2008.

[17] Y. Liu, G.-L. Chang, Y. Liu, and X. Lai, "Corridor-based emergency evacuation system for Washington, D.C. system development and case study," Transportation Research Record, no. 2041, pp. 58-67, 2008.

[18] Y.-C. Chiu and H. Zheng, "Real-time mobilization decisions for multi-priority emergency response resources and evacuation groups: model formulation and solution," Transportation Research E: Logistics and Transportation Review, vol. 43, no. 6, pp. 710-736, 2007.

[19] A. Kimms and K.-C. Maassen, "A fast heuristic approach for large-scale cell-transmission-based evacuation route planning," Networks. An International Journal, vol. 60, no. 3, pp. 179-193, 2012. 
[20] W. Yi, Z. Li, and H. Zhitong, "Coordination of connected vehicle and transit signal priority in transit evacuations," in Proceedings of the TRB 91st Annual Meeting Compendium of Papers, Washington DC, WA, USA, 2012.

[21] S. A. Ardekani and A. G. Hobeika, "Logestics Problems in the Aftermath of the Mexico-City Earthquake," Transpoertation Quarterly, vol. 42, pp. 107-124, 1988.

[22] T. J. Cova and J. P. Johnson, "A network flow model for lanebased evacuation routing," Transportation Research Part A: Policy and Practice, vol. 37, no. 7, pp. 579-604, 2003.

[23] G. Kalafats and S. Peeta, "Planning for evacuation: insights from an efficient network design model," Journal of Infrastructure Systems, vol. 15, no. 1, pp. 21-30, 2009.

[24] A. Jahangiri, P. Murray-Tuite, S. G. Machiani, B. B. Park, and B. Wolshon, "Modeling and assessment of crossing elimination for no-notice evacuations," Transportation Research Record, vol. 2459, pp. 91-100, 2014.

[25] Y. Liu, X. Lai, and G.-L. Chang, "Two-level integrated optimization system for planning of emergency evacuation," Journal of Transportation Engineering, vol. 132, no. 10, pp. 800-807, 2006.

[26] H. Sbayti and H. S. Mahmassani, "Optimal scheduling of evacuation operations," Transportation Research Record, no. 1964, pp. 238-246, 2006.

[27] Y.-C. Chiu, H. Zheng, J. Villalobos, and B. Gautam, "Modeling no-notice mass evacuation using a dynamic traffic flow optimization model," Institute of Industrial Engineers, vol. 39, no. 1, pp. 83-94, 2007.

[28] G. L. Hamza-Lup, K. A. Hua, and R. Peng, "Leveraging e-transportation in real-time traffic evacuation management," Electronic Commerce Research and Applications, vol. 6, no. 4, pp. 413-424, 2007.

[29] C. Xie and M. A. Turnquist, "Integrated evacuation network optimization and emergency vehicle assignment," Transportation Research Record: Journal of the Transportation Research Board, no. 2091, pp. 79-90, 2009.

[30] C. Xie, D.-Y. Lin, and S. Travis Waller, "A dynamic evacuation network optimization problem with lane reversal and crossing elimination strategies," Transportation Research Part E: Logistics and Transportation Review, vol. 46, no. 3, pp. 295-316, 2010.

[31] S. Liu, P. Murray-Tuite, and L. Schweitzer, "Relocating children in daytime no-notice evacuations: methodology and applications for transport systems of personal vehicles and buses," Transportation Research Record, no. 2234, pp. 79-88, 2011.

[32] P. Murray-Tuite and B. Wolshon, "Evacuation transportation modeling: an overview of research, development, and practice," Transportation Research Part C: Emerging Technologies, vol. 27, pp. 25-45, 2013.

[33] D. Handford and A. Rogers, "An agent-based social forces model for driver evacuation behaviours," Progress in Artificial Intelligence, vol. 1, no. 2, pp. 173-181, 2012.

[34] D. Ni, "Challenges and strategies of transportation modelling and simulation under extreme conditions," International Journal of Emergency Management, vol. 3, no. 4, pp. 298-312, 2006.

[35] S. H. Hamdar and H. S. Mahmassani, "From existing accidentfree car-following models to colliding vehicles exploration and assessment," Transportation Research Record, no. 2088, pp. 4556, 2008.

[36] L. D. Han, F. Yuan, and T. Urbanik, "What is an effective evacuation operation?" Journal of Urban Planning and Development, vol. 133, no. 1, pp. 3-8, 2007.
[37] B. H. Kantowitz and D. J. LeBlanc, Emerging Technologies for Vehicle Infrastructure Cooperation to Support Emergrncy Transportations Operations, Federal Highway Administrations, Washington D.C., WA, USA, 2006.

[38] S. R. Rizvi, S. Olariu, M. C. Weigle, and M. E. Rizvi, "A novel approach to reduce traffic chaos in emergency and evacuation scenarios," in Proceedings of the 2007 IEEE 66th Vehicular Technology Conference (VTC'07), pp. 1937-1941, Baltimore, MD, USA, October 2007.

[39] B. K. Mohandas, R. Liscano, and O. W. W. Yang, "Vehicle traffic congestion management in vehicular ad-hoc networks," in Proceedings of the 2009 IEEE 34th Conference on Local Computer Networks (LCN '09), pp. 655-660, Zurich, Switzerland, October 2009.

[40] A. Jotshi, Q. Gong, and R. Batta, "Dispatching and routing of emergency vehicles in disaster mitigation using data fusion," Socio-Economic Planning Sciences, vol. 43, no. 1, pp. 1-24, 2009.

[41] I. Maza, J. Capitán, J. R. Martińez-de-Dios, and A. Ollero, "Experimental results in multi-UAV coordinartion for disaster management and civil security applications," Journal of Intelligent \& Robotic Systems, vol. 61, pp. 563-585, 2011.

[42] Z. Alazawi, M. B. Abdljabar, S. Altowaijri, A. M. Vegni, and R. Mehmood, "ICDMS: an intelligent cloud based disaster management system for vehicular networks," in Lecture Notes in Computer Science (including subseries Lecture Notes in Artificial Intelligence and Lecture Notes in Bioinformatics), vol. 7266, pp. 40-56, Springer, Berlin Heidelberg, Germany, 2012.

[43] A. J. Bermejo, J. Villadangos, J. J. Astrain, and A. Córdoba, "Ontology based road traffic management," Intelligent Distributed Computing VI, vol. 446, pp. 103-108, 2013.

[44] H. Qin, X. Lu, Y. Wang, G. Wang, W. Zhang, and Y. Zhang, "Heterogeneity-aware design for automatic detection of problematic road conditions," in Proceedings of the 8th IEEE International Conference on Mobile Ad-hoc and Sensor Systems (MASS '11), pp. 252-261, October 2011.

[45] J. C. McCall and M. M. Trivedi, "Video-based lane estimation and tracking for driver assistance: survey, system, and evaluation," IEEE Transactions on Intelligent Transportation Systems, vol. 7, no. 1, pp. 20-37, 2006.

[46] mAutomotive, Connected Car Forecast: Global Connected Car Market to Grow Threefold Within Five Years, GSMA, 2013.

[47] C. K. Andersen, CAMP \& Vehicle-to-Infrastructure Applications, FHWA, 2014.

[48] R. Munarriz, "Investing Commentary," 2013, http://www.fool .com/investing/general/2013/09/27/is-fords-connected-car-athreat-to-sirius-xm.aspx.

[49] Telematics, "In-Vehicle HMI-The catalyst for strong OEMcustomer relationships," Telematics, 2013.

[50] R. N. Fries, M. R. Gahrooei, M. Chowdhury, and A. J. Conway, "Meeting privacy challenges while advancing intelligent transportation systems," Transportation Research Part C: Emerging Technologies, vol. 25, pp. 34-45, 2012.

[51] M. Abuelela, S. Olariu, and G. Yan, "Enhancing automatic incident detection techniques through vehicle to infrastructure communication," in Proceedings of the 11th International IEEE Conference on Intelligent Transportation Systems (ITSC '08), pp. 447-452, Beijing, China, December 2008.

[52] J. Adams and B. Heile, "Busy as a ZigBee," 2014, http://spectrum .ieee.org/computing/networks/busy-as-a-zigbee.

[53] R. A. Daziano, M. Sarrias, and B. Leard, "Are consumers willing to pay to let cars drive for them? Analyzing response to 
autonomous vehicles," Transportation Research Part C: Emerging Technologies, vol. 78, no. Part C, pp. 150-164, 2017.

[54] P. Bansal and K. M. Kockelman, "Forecasting Americans' longterm adoption of connected and autonomous vehicle technologies," Transportation Research Part A: Policy and Practice, vol. 95, pp. 49-63, 2017.

[55] IDOT, “Traffic Count,” 2013, http://www.gettingaroundillinois .com/gai.htm?mt=aadt.

[56] K. Bahaaldin, R. Fries, M. Williamson, and M. A. Chowdhury, "The Impact of Traffic Incident Locations on a Metropolitan Evacuation," International Journal of Transportation, vol. 4, no. 2, pp. 81-96, 2016.

[57] M. D. Rossetti and Q. Ni, "Simulating large-scale evacuation scenarios in commercial shopping districts-methodologies and case study," in Proceedings of the 2010 43rd Winter Simulation Conference (WSC'10), pp. 3494-3505, Baltimore, MD, USA, December 2010.

[58] A. Pel, M. Bliemer, and S. Hoogendoorn, Modelling Traveller Behaviour under Emergency Evacuation Conditions, Delft, Austria, European Journal of Transport and Infrastructure Research, 2011.

[59] V. P. Sisiopiku, "Application of traffic simulation modeling for improved emergency preparedness planning," Journal of Urban Planning and Development, vol. 133, no. 1, pp. 51-60, 2007.

[60] H. Mahmassani, T. Hou, and J. Dong, "Characterizing travel time variability in vehicular traffic networks: deriving a robust relation for reliability analysis," Transportation Research Record: Journal of Transportation Research Board, no. 2315, pp. 141-152, 2012.

[61] G. Gomes, A. May, and R. Horowitz, Calibration of VISSIM for a Congested Freeway, California Path Program, California, Calif, USA, 2004.

[62] Trafficware, "Synchro," 2012, http://www.trafficware.com/adaptive-traffic-control.html.

[63] PTV AG, "VISSIM 7 User Manual," Karlsruhe, 2015.

[64] F. G. Habtemichel and L. Picado-Santos, Sensitivity analysis of vissim driver behavior parameters on safety of simulated vehicles and their interaction with operations of simulated traffic, in 92nd Annual Meeting of Transportation Research Board, Washington, DC, WA, USA, 2013.

[65] T. Woody, Calibrating Freeway Simulation Models in VISSIM, University of Washington, Seattle, WA, USA, 2006.

[66] J. Hourdakis, P. G. Michalopoulos, and J. Kottommannil, "Practical procedure for calibrating microscopic traffic simulation models," Transportation Research Record, no. 1852, pp. 130-139, 2003.

[67] PTV America, “Driver Behavior Modeling," 2013.

[68] Y. Ma, M. Chowdhury, R. Fries, and K. Ozbay, "Harnessing the power of microscopic simulation to evaluate freeway service patrols," Journal of Transportation Engineering, vol. 135, no. 7, pp. 427-439, 2009.

[69] FHWA, Real-Time System Management Information Program 23 CFR Part 511, vol. 75, Washington, WA, USA, 215 edition, 2010.

[70] FDOT, Traffic Analysis Handbook, Florida Department of Transportation, Tallahassee, FL, USA, 2014.

[71] Microsoft, "Visual Studio," 2015, https://www.visualstudio.com/ products/free-developer-offers-vs.aspx.

[72] K. H. Bahaaldin, Evaluating The Impacts of Connected Vehicle Technology on Evacuation Efficiency, Southern Illinois University, Carbondale, IL, USA, 2015.
[73] R. Viereckl, D. Ahlemann, A. Koster, and S. Jursch, "Racing Ahead with Autonomous Cars and Digital Innovation," Auto Tech Review, vol. 4, no. 12, pp. 18-23, 2015. 


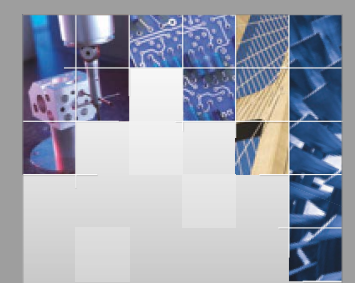

\section{Enfincering}
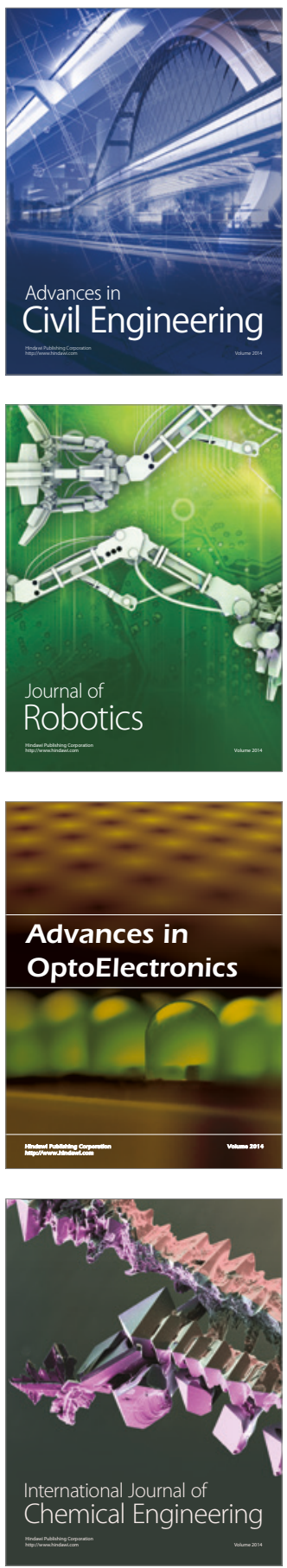

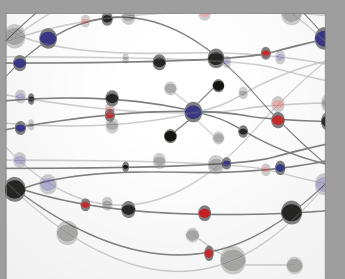

The Scientific World Journal

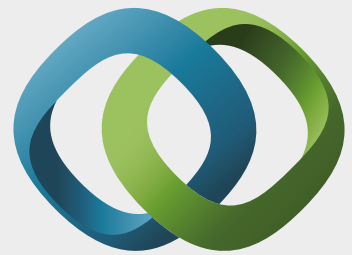

\section{Hindawi}

Submit your manuscripts at

https://www.hindawi.com
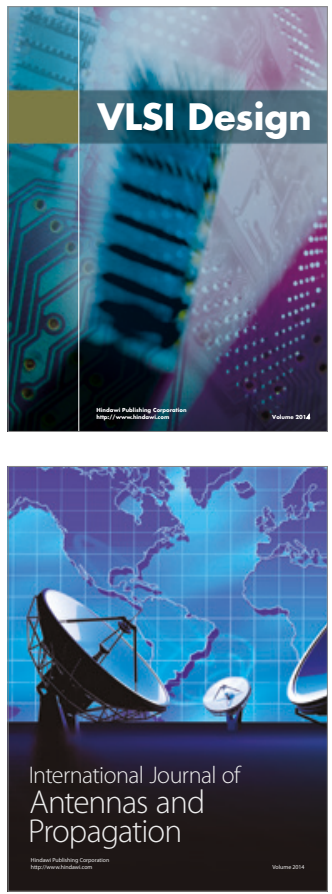

\section{Rotating}

Machinery
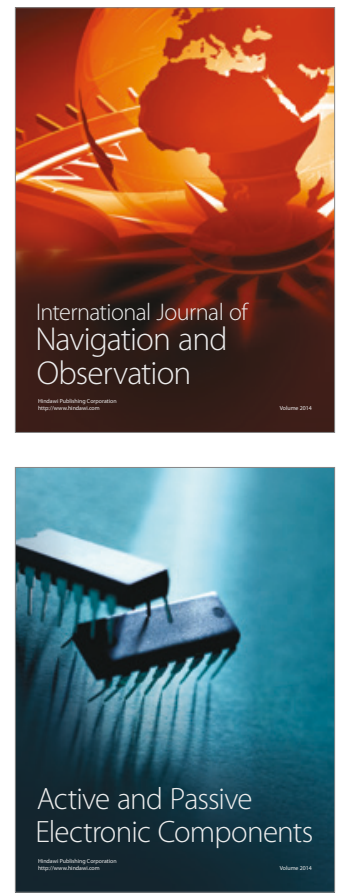
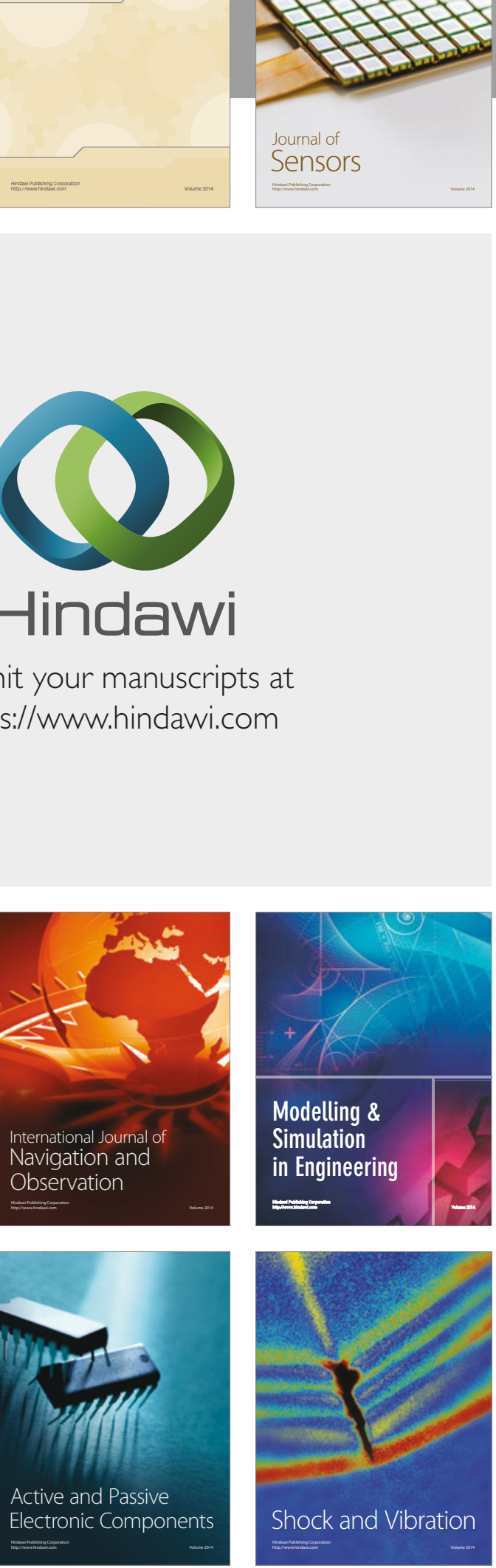
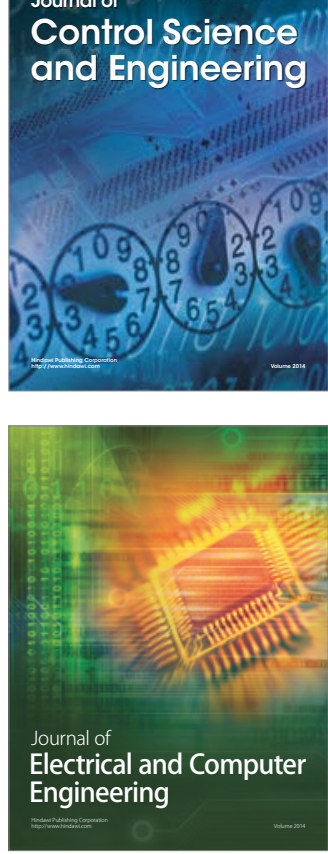

Distributed

Journal of

Control Science

and Engineering
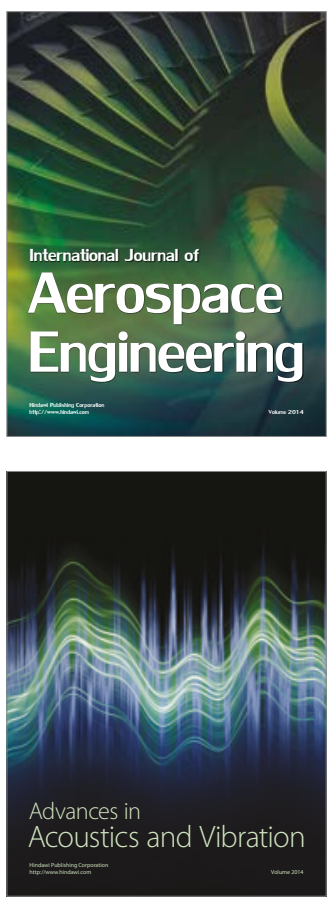

Sensor Networks 